\title{
High pressure air for pest removal from kiwifruit
}

\author{
A.B. Woolf, N.E.M. Page-Weir, R.J. Oliver, A.J. Hawthorne, A. Chhagan, D.E. Hartnett, R. Feng, A. Nangul, \\ C. McKenna, S. Dobson, K. Stannard, C. Rowe, A. Puketapu, N. Mauchline, M. Wood and L.E. Jamieson \\ The New Zealand Institute for Plant \& Food Research Limited, Private Bag 92169, Auckland 1142, \\ New Zealand \\ Corresponding author: amanda.hawthorne@plantandfood.co.nz
}

Insect removal from kiwifruit is important for improving access to overseas markets. Insect removal from kiwifruit by physical treatments such as high pressure washing is hugely successful but kiwifruit packing is carried out "dry". Therefore, one potential option is the use of 'air-knife' blowers to remove insects. A system with air-knives from the sides and top that was mounted over a single-lane Compac grader was able to remove over $90 \%$ of artificially inoculated diapausing two-spotted mites ( $\approx 85 /$ fruit). The difference in pest levels between untreated 'Hayward' kiwifruit fruit naturally infested with a wide range of insects $(n=2194)$ and fruit exposed to air-knives $(n=2204)$ was: mealybug $100 \%$, beetle/weevils 91-100\%, oribatid mites $93 \%$, tuckerellid mites $98 \%$, unidentified mites $88 \%$, booklice $86 \%$, thrips $74-$ $100 \%$, Collembola $63 \%$, cockroaches $100 \%$, spiders $43 \%$, scale insects $40 \%$. Air-knives had no noticeable effect on 'Hayward' or 'Zesy002' (Gold3) fruit quality. These results indicate that air-knives using a high air-flow/low-pressure system can effectively remove high rates of "mobile" insects and first-instar scale insects, and can probably be implemented logistically and economically from a commercial perspective.

\section{Pre-treatment dips to enhance the removal of apple leafcurling midge from apples using high pressure washing}

\author{
N.E.M. Page-Weir, L.E. Jamieson, A.J. Hawthorne, S.P. Redpath, A. Chhagan, D.E. Hartnett, L. Guo and
} A.B. Woolf

The New Zealand Institute for Plant \& Food Research Limited, Private Bag 92169, Auckland 1142, New Zealand

Corresponding author: Natalie.Page@plantandfood.co.nz

The presence of apple leafcurling midge (ALCM) on apples is of concern for many of New Zealand's export apple markets. High pressure washing (HPW) systems have been implemented in export packhouses to reduce the risks associated with various pests; however, higher removal rates of ALCM are required to improve access to challenging markets. A range of pre-treatment dips to improve ALCM removal efficacy when applied before HPW were tested, and the impact of these pre-treatment dips on pest viability determined. Removal of ALCM cocoons by HPW alone was $41 \%$, compared with pretreatments of hot water at $51^{\circ} \mathrm{C}(66 \%)$, Saturate ${ }^{\circledR}(58 \%)$, Prospect oil ${ }^{\circledR}(57 \%)$, malic acid (53\%), citric acid (48\%), lactic acid (46\%), acetic acid (39\%), HarvestCide ${ }^{\circledR}(37 \%)$ or sodium bicarbonate $(37 \%)$. However, only the hot-water treatment significantly enhanced removal compared with HPW alone. In a second trial, removal of ALCM cocoons with HPW was $69 \%$ and hot water + UV-C increased removal to $76 \%$, although this difference was not statistically significant. Overall, none of the pre-treatment dips was found to reduce ALCM viability significantly compared with HPW alone. 